Thomas Flament

Julie Mankikian

Emmanuelle Mercier

\section{Ultrasound-guided insertion of dialysis catheter in the prone position}

Received: 1 November 2013

Accepted: 24 January 2014

Published online: 12 February 2014

(C) Springer-Verlag Berlin Heidelberg and ESICM 2014

Electronic supplementary material The online version of this article (doi:10.1007/s00134-014-3229-4) contains supplementary material, which is available to authorized users.

T. Flament ( $)$ - J. Mankikian · E. Mercier Service de Réanimation Médicale, Centre Hospitalier Universitaire de Tours, 37044, Tours Cedex, France

e-mail: thomas_pierre.flament@hotmail.fr

A 66-year-old man was admitted to the intensive care unit for a septic shock with acute renal failure and acute respiratory distress syndrome (ARDS) with a $\mathrm{PaO}_{2} / \mathrm{FiO}_{2}$ ratio of $72 \mathrm{mmHg}$, an $\mathrm{FiO}_{2}$ of $90 \%$, a PEEP of $10 \mathrm{cmH}_{2} \mathrm{O}$, and a tidal volume of $6 \mathrm{ml} / \mathrm{kg}$ of predicted body weight ventilation.

The patient was turned to the prone position (PP) on the first day of admission. During the PP period, he presented anuric renal failure.

The first studies related to the potential use of PP in ARDS treatment were published in 2011.

The Proning Severe ARDS Patients (PROSEVA) group demonstrated the beneficial effect of a prolonged PP session during mechanical ventilatory support in a recent study.

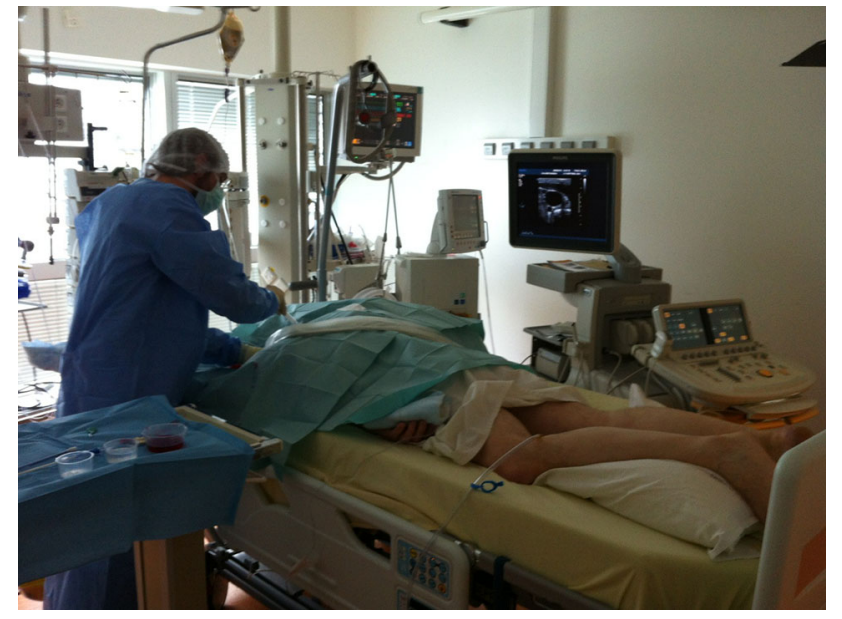

Fig. 1 Ultrasound-guided insertion of the needle in the left jugular

Sepsis-associated acute kidney injury was associated with a poor prognosis, substantiated by mortality rates of up to $75 \%$.

In this context, we decided to maintain the PP session and to insert the dialysis catheter under ultrasound guidance (Fig. 1) in the left jugular by the posterior approach (Supplemental Fig. 1). We controlled the catheter placement by chest X-ray in the PP (Supplemental Fig. 2), no complication was observed and haemodialysis was started during the PP session.

Conflicts of interest The authors declare that they do not have any conflict of interest. 